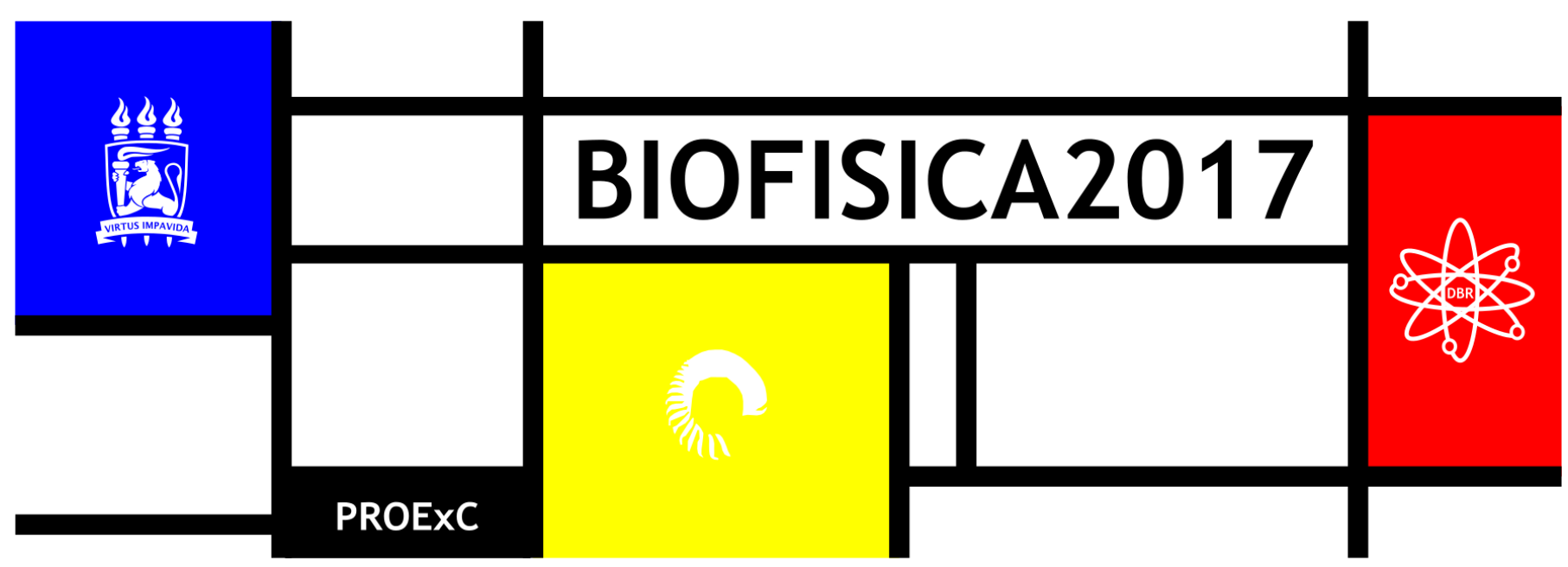

\title{
AVALIAÇÃO DA ATIVIDADE ANTIOXIDANTE DE TINTURA A BASE DE Solidago chilensis Meyen COMERCIALIZADOS EM ARRANJOS PRODUTIVOS LOCAIS EM PERNAMBUCO
} Marilia Grasielly de Farias Silva ${ }^{1 *}$, Beatriz Santana Rocha ${ }^{1}$, Rafael Jorge Santos Aracati Padilha ${ }^{1}$, Leylianne de Cássia
Rodrigues Nerys ${ }^{1}$, Rafhael Miguel da Silva ${ }^{1}$, Ricardo Yara ${ }^{2}$, Cláudia Sampaio Andrade Lima ${ }^{1}$

${ }^{1}$ Laboratório de Biofísica Química - Departamento de Biofísica e Radiobiologia - UFPE; ${ }^{2}$ Departamento de Engenharia Biomédica-UFPE *beatrizsantanarocha@gmail.com

\section{INTRODUÇÃO}

Solidago chilensis é uma espécie da família Asteraceae, conhecida popularmente como "erva-lanceta", e destaca-se por ser matériaprima de variados medicamentos oriundos do conhecimento popular, sendo empregados pela população por apresentar redução de sintomas inflamatórios, cicatrizantes, antissépticos e distúrbios osteomusculares (VALVERDE et al., 2012).

As propriedades terapêuticas possivelmente estão relacionados aos metabólitos secundários das plantas, que são compostos orgânicos produzidos pelos vegetais para a sua defesa (YUNES \& CECHINELFILHO, 2001). As classes de metabólitos secundários, normalmente associados a estas propriedades são os compostos fenólicos como os flavonoides, fenóis, taninos, e cumarinas, além de alcaloides, saponinas, entre outros (SOUZA, 2009). Os compostos fenólicos possuem estruturas variáveis, possuindo características multifuncionais, podendo estar presente, por exemplo, em atividades antioxidantes (TAIZ \& ZEIGER, 2004).

$\mathrm{Na}$ literatura consta que substâncias de ação antioxidante podem agir em pacientes com artrite reumatoide e outros transtornos ósseos, proporcionando uma defesa contra o estresse oxidativo, pois poderiam atuar sobre os radicais livres prevenindo certas patologias

A erva lanceta é utilizada para a produção de um fitoterápico e comercializada em arranjos produtivos locais de Pernambuco, oferecendo a população um produto que alivia dores nas articulações, e tratamento natural para artrite e artrose. Entre os fitoterápicos, as tinturas (filtrados alcoólicos a base de partes das plantas) são bastante aceitos pela população.

$\mathrm{Na}$ literatura consta que substâncias de ação antioxidante podem agir em pacientes com artrite reumatoide e outros transtornos ósseos, proporcionando uma defesa contra o estresse oxidativo, pois poderiam atuar sobre os radicais livres prevenindo certas patologias.

Diante do exposto, o presente trabalho teve como principal objetivo avaliar o potencial antioxidante do extrato bruto de Solidago chilensis e de sua tintura, e, a partir desses resultados, comparar suas atividades e ponderar a potencialização ou não dos seus efeitos.

\section{MATERIAIS E MÉTODOS}

A espécie Solidago chilensis Meyen foi coletada na Comunidade do Conjunto Muribeca, Jaboatão dos Guararapes (PE). A tintura foi igualmente fornecida por um arranjo produtivo local do mesmo município, no primeiro semestre de 2016. Após a coleta o material foi submetido a identificação, enquanto que uma parte do mesmo foi acondicionado em estufa de secagem, expostas a uma temperatura de $45^{\circ} \mathrm{C}$ com circulação forçada de ar. Após trituração e filtração, o material vegetal foi destilado à vácuo em evaporador rotativo (RV 10 Control da IKA), com temperatura máxima de $45^{\circ} \mathrm{C}$ para a obtenção do extrato bruto, que posteriormente, foi colocado em dessecador, para peso constante. As tinturas também foram evaporadas sob pressão reduzida para obtenção do extrato. Foi realizada a análise da atividade antioxidante da tintura e do extrato bruto da erva lanceta através do teste de redução do DPPH (2,2-difenil-1- picrilhidrazil). Este baseia-se na transferência de elétrons onde, por ação antioxidante, altera a cor da solução de púrpura para amarelo. A partir dos resultados obtidos determinouse a porcentagem de atividade antioxidante ou sequestradora de radicais livres (NASCIMENTO et al., 2011).

A partir do extrato etanólico foram preparadas soluções das amostras nas seguintes concentrações: 100, 80, 60, 40 e $20 \mu \mathrm{g} / \mathrm{mL}$. Um controle negativo foi feito pela adição de etanol e DPPH, Adicionou-se a cada concentração de extrato etanólico uma solução de DPPH $300 \mu \mathrm{M}$, exceto nos brancos, onde foi adicionado o solvente. Dois controles positivo foram utilizados (BHT e Ácido ascórbico) e a tintura fornecida foram ainda comparados com o extrato nas mesmas concentrações. Todos os testes foram realizados em triplicata. Após a adição do DPPH nas soluções, esperou-se 30 minutos, em ambiente protegido da luz, para a realização da leitura em espectrofotômetro de UV-Vis a $515 \mathrm{~nm}$. A capacidade de eliminar o radical DPPH (\% de atividade antioxidante) foi calculada utilizando-se a seguinte equação: 
$\% \mathrm{AA}=100-\left\{\left[\left(\mathrm{Abs}_{\text {amostra }}-\mathrm{Abs}\right.\right.\right.$ branco $\left.\left.) \times 100\right] / \mathrm{Abs}_{\text {controle }}\right\}$

Para a obtenção da curva de calibração preparou-se uma solução etanólica de DPPH na concentração de $300 \mu \mathrm{Mol}(120 \mu \mathrm{g} / \mathrm{mL})$. Em seguida, foram preparadas diluições dessa solução para obtenção de diferentes concentrações $100,80,60,40,20,10,5$ e $1 \mu \mathrm{g} / \mathrm{mL}$. Foram feitas as leituras das absorbâncias das soluções, em triplicata, utilizando-se etanol como branco. Foi construída a curva padrão de DPPH plotando-se o valor médio das absorbâncias obtidas $x$ concentração da solução (NASCIMENTO et al., 2011). Devido a importância de compostos fenólicos como os flavonóides na atividade antioxidante foi realizada uma análise comparativa espectrofotométrica (UV-visível) no extracto de Solidago chilensis, quercetina e rutina utilizando um espectrofotómetro UV-visível (Shimadzu UV-vis 1800). 0 extracto e padrões foram examinado sob luz visível e UV no comprimento de onda que varia de 200-800 nm.

\section{RESULTADOS E DISCUSSÃO}

A análise dos resultados comparou a atividade antioxidante do extrato bruto da folha da erva lanceta com a tintura e foi escolhido o ácido ascórbico e o BHT porque são os controles positivos mais usados na literatura (SHARIAH et al., 2013) (Tabela 1).

Tabela 1. Análise da atividade antioxidante (DPPH \%). Legenda: A.A.(ácido ascórbico); BHT (di-terc-butil metil fenol); E.B.(Extrato Bruto) e T. (tintura).

\begin{tabular}{cccccc}
\hline \multicolumn{5}{c}{ Concentração $(\mu \mathrm{g} / \mathrm{ml})$ em \% } \\
\hline & 100 & 80 & 60 & 40 & 20 \\
\hline \multirow{2}{*}{ A.A } & 96,75 & 96,54 & 96,37 & 94,87 & 93,2 \\
& $\pm 0,07$ & $\pm 0,07$ & $\pm 0,11$ & $\pm 0,10$ & $\pm 0,17$ \\
& 78,09 & 65,32 & 56,77 & 42,51 & 30,78 \\
BHT & $\pm 0,05$ & $\pm 0,02$ & $\pm 0,43$ & $\pm 0,06$ & $\pm 0,02$ \\
& 34,92 & 27,2 & 20,4 & 13,6 & 6,8 \\
E.B & $\pm 0,28$ & $\pm 0,19$ & $\pm 0,14$ & $\pm 0,05$ & $\pm 0,03$ \\
& 10,23 & 7,54 & 4,28 & 1,64 & 8,93 \\
T. & $\pm 0,89$ & $\pm 0,38$ & $\pm 0,74$ & $\pm 0,16$ & $\pm 0,93$
\end{tabular}

O extrato bruto apresentou quase $30 \%$ mais atividade antioxidante quando comparada a tintura. Isso indica que as tinturas podem ter sido preparadas de maneira inadequada, para isso é necessária uma investigação em lotes dos produtos e sazonalidade sobre a coleta do material em análise assim como sugerir outros testes bioquímicos para comprovar os agentes antioxidantes.

Poucos trabalhos na literatura tem relacionado à atividade antioxidante de tinturas com o extrato bruto de plantas e se faz necessária uma investigação mais detalhada com fitoterápicos comercializados em Pernambuco, visto que em 2005, já tinha sido relatado mais de 500 produtos a base de plantas vendidos na região metropolitana do Recife (NASCIMENTO et al 2005).

Güntne e colaboradores (1999) sugeriram a presença de flavonoides glicosilados em flores que seriam responsáveis pelo combate dos radicais livres. Quando comparados com o padrão BHT comercial estes compostos apresentaram uma ação antioxidante significantemente maior. Reconhecendo a importância dos compostos fenólicos na atividade antioxidante foi realizada uma análise comparativa com 2 padrões de flavonoides a quercetina e a naringina (Figura 1).

0 perfil da S. chilensis mostrou picos na região de 329, 410 e $670 \mathrm{~nm}$. Não foram observados picos característicos da narigina e quercetina no extrato bruto da erva lanceta, contudo, uma purificação por técnicas cromatográficas poderia evidenciar a presença desses compostos, que já foram destacadas na literatura (SKRZYPCZAK, 2001; VECHIA et al., 2016)

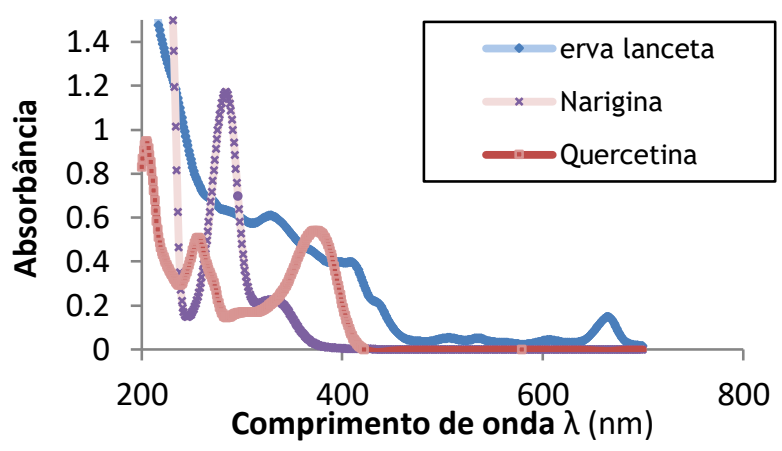

Figura 1. Análise comparativa do perfil espectrofotométrico do extrato da erva lanceta e de dois flavonoides ( $r$ da atividade antioxidante (DPPH \%).

\section{CONCLUSÃO}

Neste trabalho, as tinturas apresentaram baixa atividade antioxidante quando comparados com o extrato bruto da planta, sugerindo melhoras no meio da preparação da tintura. Além disso, este trabalho contribui para o conhecimento de fitoterápicos (tinturas), fabricados no Estado de Pernambuco, além do seu potencial antioxidante.

\section{REFERÊNCIAS}

GUNTNER, C. BARRA, C., CELSIO, M. V. DELLACASSA, E. FERRANDO, L. FERREIRA, F. GARCIA, C., GONZALES, G. HEINZEN, H. LLIORET, A. LORENZO, D., MENÉNDEZ, P., PAZ D., SOULE, S., VÁSQUEZ, A., MOYNA P. Antioxidant properties of Solidago chilensisl. Flavonoids II WocMAP Congress Medicinal and Aromatic Plants, Part 2: Pharmacognosy, Pharmacology, Phttomedicine, Toxicology. ISHS Acta Horticultrae 501, 1999.

NASCIMENTO, J. E.; LACERDA, E. U. NASCIMENTO, V.T.; MELO, J. G.; ALVES, B. S.; SILVA, L. G. M.; RAMOS, M. A.; LIMA, C. S. A.; ALBUQUERQUE, U. P.; AMORIM, E. L. Produtos à Base de Plantas Medicinais Comercializadas em Pernambuco Nordeste do Brasil, Recife- PE. Acta Farm., Bonaerense 24, v.(1),p. 113-22, 2005.

NASCIMENTO J.C., LAGE L.F.O, CAMARGOS C.R.D, AMARAL J.C, COSTA L.M., SOUSA N.A, OLIVEIRA F.Q. Determinação da atividade antioxidante pelo método DPPH e doseamento de flavonóides totais em extratos de folhas da Bauhinia variegata L. Rev. Bras. Farm., v. 92 (4), P. 327-332, 2011.

SHARIAH, M. HOSSAI, M. I.; SHARMIM, F. A. AKHTER, S.; HAQUE, Md. A. BHUIYAN, M. A. In Vitro Antioxidant and free Radical Scavenging activity of Withania Sommifera Root. Iosr Journal of Pharmacy, v.3 (2) p. 38-47, 2013.

SKRZYPCZAK, LUTOSLAWA; BUDZIANOWSKI, JAROMIR. Phenolic compounds in two Solidago L. species from in vitro culture. Acta Pol. Pharm, v. 58, p. 277-281, 2001.

SOUZA, T.M., SEVERI, J.A., SILVA, V.Y.A., SANTOS, E., PIETRO, R.C.L.R. Bioprospecção de atividade antioxidante e antimicrobiana da casca de Stryphnodendron adstringens (Mart.) Coville (Leguminosae-Mimosoidae).Revista de Ciências Farmacêuticas Básica e Aplicada, v. 28(2), p. 221-226, 2009.

TAIZ, L. ZEIGER, E. Fisiologia vegetal. 3d. Porto Alegre. Artmed, 719p. 2014

VALVERDE, S. S.; OLIVEIRA, T.B.; SOUZA, S. P. Solidago chilensis Meyen (asteraceae). Revista Fito, v. $7-n^{\circ} 03,2012$.

VECHIA, C. A. D.; MORAIS, B.; SCHONELL, A. P.; DIEL, K. A. P.; FAUST, C; MENIN, C.; GOMES, D. B.; ROMAN, JUNIOR W. A. Isolamento químico e validação analítica por cromatografia líquida de alta eficiência de quercitrina em Solidago chilensis Meyen (Asteraceae). Rev. Bras. PI. Med., Campinas, v.18, n.1, supl. I, p.288-296, 2016.

YUNES, R. A., CECHINEL FILHO, V. Breve Análise Histórica da Química de Plantas Medicinais: sua importância na atual concepção de fármaco segundo os paradigmas ocidental e oriental. Plantas Medicinais sob a ótica da Química Medicinal Moderna. Chapecó: Argos, 2001. 